\title{
混合軟亳中のハイドロコルチゾン-17-ブチレートの安定性
}

\author{
安達秀夫, 大島和夫, 黒澤嘉幸 \\ 阪衛医科大学校病院薬郕部*
}

\section{The Stability of Hydrocortisone-17-Butyrate in the Admixture of Ointments}

\author{
HIDEO ADACHI, KAZUO OSHIMA and YoshIYUKI KUROSAWA \\ Department of Hospital Pharmacy, National Defense Medical College*
}

(Received August 6, 1987)

\begin{abstract}
The stability of hydrocortisone-17-butyrate (HC-17-B) in the admixture of Locoid $\otimes$ Ointment with Anderm ${ }^{\circledR}$ Ointment (AO), zinc oxide (10\%) ointment (ZO) or Juvela Ointment (JO) was investigated by the quantitative analysis using high performance liquid chromatography. The decomposition routes of $\mathrm{HC}-17-\mathrm{B}$ to hydrocorisone-21-butyrate (HC-21-B) and hydrocortisone (HC) in such ointment admixtures were also investigated.

In the stability test, percentages of the residual active $\mathrm{HC}-17-\mathrm{B}$ and decomposition products in the admixtures immediately after mixing and after $2,4,8$ and 12 weeks of storage in darkness at $5^{\circ} \mathrm{C}, 25^{\circ} \mathrm{C}$ or $40^{\circ} \mathrm{C}$ were investigated. As a result, it was found that the admixture with $\mathrm{AO}$ of a white petrolatum base was stable under any of the storage conditions. In the admixture with $\mathrm{ZO}, \mathrm{HC}-17-\mathrm{B}$ was stable at $5^{\circ} \mathrm{C}$ but it decomposed after storage at $25^{\circ} \mathrm{C}$ or higher temperature, resulting in the formation of $\mathrm{HC}-21-\mathrm{B}$ and $\mathrm{HC}$. In the admixture with a JO of o/w type hydrophilic ointment base, $\mathrm{HC}-17-\mathrm{B}$ decomposed under any of the storage conditions, and with the rise in storage temperature the level of $\mathrm{HC}-17-\mathrm{B}$ decreased quickly while the level of HC-21-B increased rapidly first, then decreased slowly with the gradual increase in the level of $\mathrm{HC}$.
\end{abstract}

Keywords — - hydrocortisone-17-butyrate ; hydrocortisone-21-butyrate ; hydrocortisone ; stability ; decomposition product ; admixture

\section{緒}

急性湿疹及び皮膚炎等に繁用されているロコイド® 軟 高の主成分であるハイドロコルチゾン-17-ブチレート (HC-17-B) は，オランダの Gist Brocades 社で開発さ れた副腎皮質ホルモンで，ハイドロコルチゾン (HC) の 17位を酪酸でェステル化し， HC 飞比べ作用の増強 ${ }^{1)}$ 及 び副作用の軽減 ${ }^{2 \sim 3)}$ 等で効果があるといわれている. 軟 高中の HC-17-B の安定性は, 一般に保存温度及び軟膏 中の $\mathrm{pH}$ に左右されやすく， ハイドロコルチゾン-21-ブ チレート (HC-21-B) と HC に分解することが知られて

* 埼玉県所沢市並木3-2; 3-2, Namiki, Tokorozawashi, Saitama, 359 Japan
(る⿱艹).

副腎皮質ホルモン軟膏は，他の軟衰と混合使用する例 が多く，当院皮膚科においてもロコイド囚 軟高と他の軟 高を混合する処方が数種あったので，著者らはロコイ ド® 軟膏と他の軟育とを混合した 3 種類の軟膏中のHC17-B の安定性を, さらに分解物である $\mathrm{HC}-21-\mathrm{B}$ 及び $\mathrm{HC}$ の生成過程について高速液体クロマトグラフィー (HPLC) を用いて検討を行った.

\section{实 験 の 部}

\section{1. 試 薬}

HC-17-B の軟育としてロコイド®軟高 (Lot No. LPE12N）を用い，混合した軟育は当院に打いて実際に 処方される中で頻度の高いアンダーム® 軟高 (Lot No. 
348), ユベラ®軟高 (Lot No.5104), 亜鉛華 (10\%) 単軟亳「ヨシダ」(Lot No.085758) の3 種類とした. HC-17-B は鳥居薬品から提供を受け, HC は市販品 （和光純薬,試薬特級）を使用した. HC-21-B は HC と 無水 $\mathrm{n}$ 一酪酸をピリジン中で氷冷下反応させて合成した 白色結晶性粉末で, HPLC で不純物を含有していない ことを確認し，MASS 及びプロトン NMR スペクトル で HC の 21 位に n-酪酸が ェステル結合していることを 確認した上で標準品として使用した．また，テトラヒド ロフラン (THF), メタノールは高速液体クロマトグラ フ用溶媒 (関東化学) を用いた.

\section{2. 混合軟言の調製}

ロコイド®軟育と他の軟膏との混合比は, 混合処方中 の約 $80 \%$ が等量混合であったため, 実験は等量混合軟 育とし, 処方は Table 1 に示す 3 種類について行った. ロコイド®軟育と各軟膏を各々 $50 \mathrm{~g}$ 量りとり, 軟亮ベラ で十分混和練合し，HPLC で HC-17-B が均等に分散さ れていることを確認してから試料軟高とした.

Table 1. Formula of Ointment

\begin{tabular}{|c|c|}
\hline \multicolumn{2}{|l|}{ Rp. 1} \\
\hline Locoid ${ }^{\circledR}$ Ointment & $50 \mathrm{~g}$ \\
\hline Anderm ${ }^{\circledR}$ Ointment & $50 \mathrm{~g}$ \\
\hline Total & $100 \mathrm{~g}$ \\
\hline \multicolumn{2}{|l|}{ Rp. 2} \\
\hline Locoid ${ }^{\circledR}$ Ointment & $50 \mathrm{~g}$ \\
\hline \multicolumn{2}{|l|}{ Zinc Oxide $(10 \%)$} \\
\hline Ointment $(\mathrm{ZO})$ & $50 \mathrm{~g}$ \\
\hline Total & $100 \mathrm{~g}$ \\
\hline \\
\hline \multicolumn{2}{|l|}{ Rp. 3} \\
\hline Locoid $\otimes$ Ointment & $50 \mathrm{~g}$ \\
\hline Juvela $\otimes$ Ointment & $50 \mathrm{~g}$ \\
\hline Total & $100 \mathrm{~g}$ \\
\hline
\end{tabular}

\section{HC-17-B， HC-21-B 及び HC の同時分析と定量}

\section{条件}

同時分析条件を種々検討した結果, 装置 : ウォーター ズモデル 206,カラム: Nucleosil 5 C18 $(4.6 \times 150 \mathrm{~mm})$, 検出波長 : $254 \mathrm{~nm}$, 移動相: アセトニトリルー水 (45: 55), 流速 : $1 \mathrm{ml} / \mathrm{min}$ とした.

この条件で測定した結果を Fig. 1 に示す. 保持時間約 3 分に HC が, 8 分に HC-17-B が, 11 分に HC-21-B
がそれぞれ検出され，よく分離されたため, 以後の実験 はこの条件に従って行った.

次に，本法を用いて定量のための検量線をFig. 2 に示 す. HC-17-B， HC-21-B 及び HC の $0 \sim 300 \mathrm{ng}$ の濃度 内でそれぞれ縦軸にピーク面積, 横軸に濃度をとったと ころ,プロットした点は原点を通る良好な直線を得た。

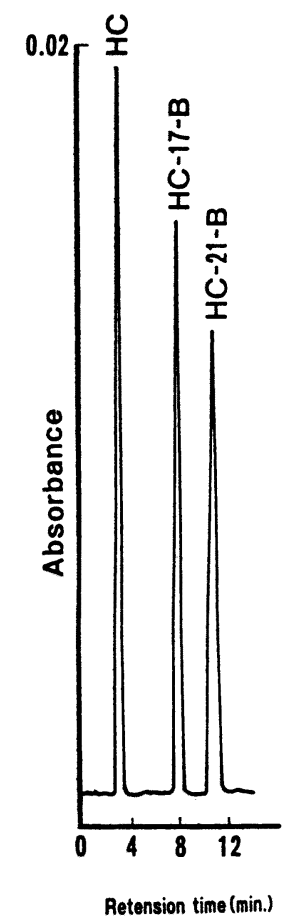

Equipment : Waters' Analytical Liquid Chromatograph Model 206

Column : Nucleosil $5 \mathrm{C}_{18}$ $(5 \mu \mathrm{m}, 4.6 \mathrm{~mm} \times 15 \mathrm{~cm}$, Nagel)

Mobil Phase : $\mathrm{CH}_{3} \mathrm{CN}: \mathrm{H}_{2} \mathrm{O}$ $=45: 55$

Temperature : Ambient Flow Rate $: 1.0 \mathrm{ml} / \mathrm{min}$ Colum Pressure : 1200psi Detector : UV 254nm Sample Size : HC

HC-17-B 150ng HC-21-B 150ng

Fig. 1. Chromatogram of HC-17-B, $\mathrm{HC}-21-\mathrm{B}$ and $\mathrm{HC}$

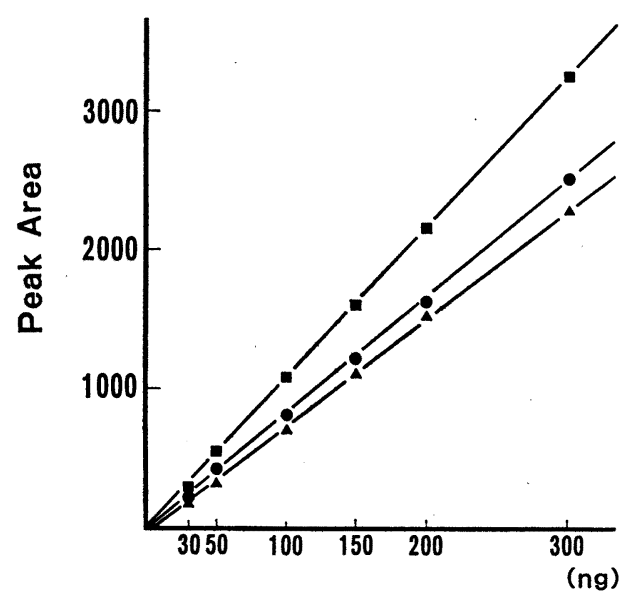

Fig. 2. Calibration Curves for $\mathrm{HC}-17-\mathrm{B}$, $\mathrm{HC}-21-\mathrm{B}$ and $\mathrm{HC}(\mathrm{O}, \mathrm{HC}-17-\mathrm{B} ; \boldsymbol{\Delta}$, $\mathrm{HC}-21-\mathrm{B} ; \mathbf{\square}, \mathrm{HC}$ ) 
Table 2. Reproducibility of $\mathrm{HC}-17-\mathrm{B}$, $\mathrm{HC}-21-\mathrm{B}$ and $\mathrm{HC}$

\begin{tabular}{cccc}
\hline \hline \multirow{2}{*}{$\begin{array}{c}\text { Injection } \\
\text { No. }\end{array}$} & \multicolumn{3}{c}{ Peak Area Ratio } \\
\cline { 2 - 4 } 1 & HC-17-B & HC-21-B & HC \\
2 & 1676 & 1491 & 2098 \\
3 & 1649 & 1529 & 2169 \\
4 & 1635 & 1544 & 2105 \\
5 & 1621 & 1516 & 2085 \\
$\bar{x}$ & 1682 & 1501 & 2155 \\
C. V. (\%) & 1653 & 1516 & 2122 \\
\hline
\end{tabular}

Table 3. Recovery and Reproducibility of $\mathrm{CH}-17-\mathrm{B}$ in Admixtures

\begin{tabular}{lcc}
\hline \hline Admixed Material & Recovery(\%) & C.V.(\%) \\
\hline Anderm ${ }^{\otimes}$ Ointment & 99.7 & 1.8 \\
Zinc Oxide Ointment & 98.7 & 1.6 \\
Juvela ${ }^{\circledR}$ Ointment & 96.5 & 1.2 \\
\hline
\end{tabular}

All data show mean values of 5 experiments.

また，各ステロイド 200ng の 5 回繰り返しによる注入 時の再現性は Table 2 に示すように, 変動係数がいず れも $1.8 \%$ 以下であり, 絶対検量線法で十分に定量し得 るものと考光た.

\section{4. 混合軟融らの HC-17-B の抽出方法}

混合軟高からの HC-17-B の抽出は, 試料 $1 \mathrm{~g}$ 飞 THF $5 \mathrm{ml}$ を加光て振とう溶解し, メタノール $16 \mathrm{ml}$ を加えて 振とうし, 基剤成分を沈降させる. 次に, 水 $2 \mathrm{ml}$ を加 えて振とらし, 残りの基剤成分を沈降させ, さらに水を 加えて全量を $25 \mathrm{ml}$ とする. この上澄液をメンブランフ イルター（マイレックス®SR, ミリポア社）でろ過後検 液とし，その $10 \mu 1$ をHPLC に注入し定量を行った. 本法による抽出方法で, 基剤等の妨害ピークは認められ なかった. Table 3 飞 HC-17-B の回収率及びその変動 係数を示す.

\section{5. 混合軟滈の安定性試験}

混合軟高の調製直後と $5^{\circ} \mathrm{C}, 25^{\circ} \mathrm{C}$ 及び $40^{\circ} \mathrm{C}$ で遮光 保存し，2，4，8 及び 12 週間後の外観の観察と HC17-B の残存率と $\mathrm{HC}$ 及び HC-21-B の生成率を求め た.

\section{結果及び考寮}

\section{混合㳄需中の HC-17-B の経時变化}

$5{ }^{\circ} \mathrm{C}, 25^{\circ} \mathrm{C}$ 及び $40^{\circ} \mathrm{C}$ 各遮光保存下, ロコイド®軟 高との混合軟亭中の HC-17-B の12週間の安定性成績の 残存率を実線 で，また，HC-21-B と HC の生成過程を 破線で Fig. 3〜 5 亿示す.

アンダーム®軟育との混合では, Fig.3に示すように すべての条件で HC-17-B は安定であった．しかし， $40^{\circ} \mathrm{C}$ 保存の 2 週以降, 軟育の外観にブリーディング現 象が観察された.

亜鉛華 $(10 \%)$ 単軟育と混合した場合，Fig. 4 亿示す ように HC-17-B は $5^{\circ} \mathrm{C}$ 保存では安定であったが， $25{ }^{\circ} \mathrm{C}$ では時間の経過にともない徐々に分解し，12週間 で $80 \%$ に， $40^{\circ} \mathrm{C}$ ではさらに分解し，12週間で $13 \%$ に 含有量は低下した。 $\mathrm{HC}-21-\mathrm{B} は 5^{\circ} \mathrm{C}$ 保存では生成され なかったが, $25^{\circ} \mathrm{C}$ で 8 週目から， $40^{\circ} \mathrm{C}$ では 2 週目か ら生成し, $40^{\circ} \mathrm{C}, 12$ 週間で $40 \%$ 生成した. $\mathrm{HC} 5^{\circ} \mathrm{C}$ 保存では生成されなかったが, $25^{\circ} \mathrm{C}$ と $40^{\circ} \mathrm{C}$ で少量では あったが生成した．しかし，いずれの場合る軟高の外観 に変化は観察されなかった.

ユベラ®軟高と混合した場合，Fig. 5 飞示すように， ぞのような保存条件です HC-17-Bに分解がみられた。 $5{ }^{\circ} \mathrm{C}$ 保存 12 週間で $47 \%$ に, $25{ }^{\circ} \mathrm{C}, 8$ 週間で $2.2 \%$ 亿, $40^{\circ} \mathrm{C}, 4$ 週間で $1.3 \%$ と保存温度の上昇にともない急激 飞低下した. HC-21-B は $5^{\circ} \mathrm{C}$ 保存では徐々飞增加し たが, $25^{\circ} \mathrm{C}$ では急激に増加した後 プラトーになり,さ らに $40^{\circ} \mathrm{C}$ では急激に增加した後, 徐々に低下する傾向 が見られた. HC る保存温度の上昇にとるない徐々飞增 加してくるが，その後徐々に低下した。 そして，40ㄷ 保存の 2 週以降, 軟高の外観に水分分離が観察され, 色 調もクリーム色から黄色に変化した.

以上の結果, 混合軟育中の HC-17-B の安定性は保存 温度及び混合する軟高により大きな違いがみられた，こ の違いは混合した軟膏の基剤の種類，または混合した軟 亳中の主成分との相互作用によるものと推測される。

白色ワセリンを基片とするアンダーム®軟高とでは, HC-17-B はどのような保存条件でる 安定であるが, 亜 鉛華 $(10 \%)$ 単軟育とでは保存温度の違いにより経時変 化がみられたため冷所保存が必要と思われた。水中油型 の親水性軟膏を基剤とするユベラ®軟高とでは，どのよ らな保存条件でも分解するため混合軟高の調製はすべき ではなく，必要であれば個別に塗布するのがよいと思わ れた。 


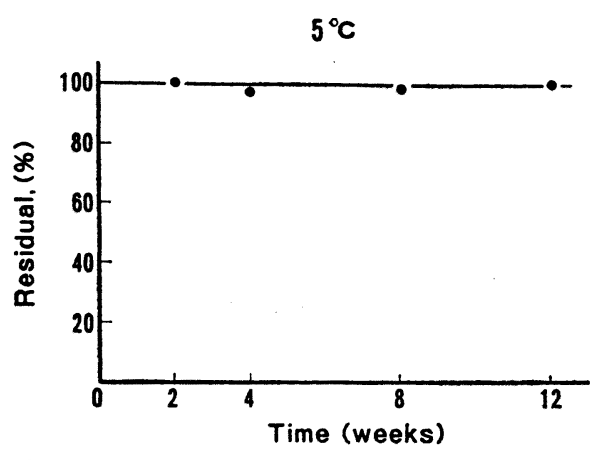

$25^{\circ} \mathrm{C}$

$40^{\circ} \mathrm{C}$
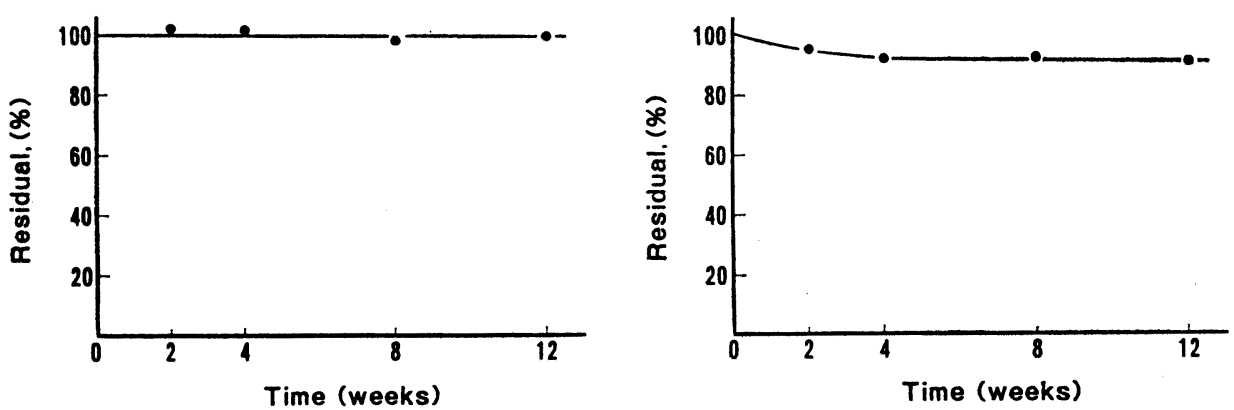

Fig. 3. Stability of $\mathrm{HC}-17-\mathrm{B}$ in Locoid ${ }^{\otimes}$ Ointment Admixed with Anderm ${ }^{\circledR}$ Ointment , $\mathrm{HC}-17-\mathrm{B}$.
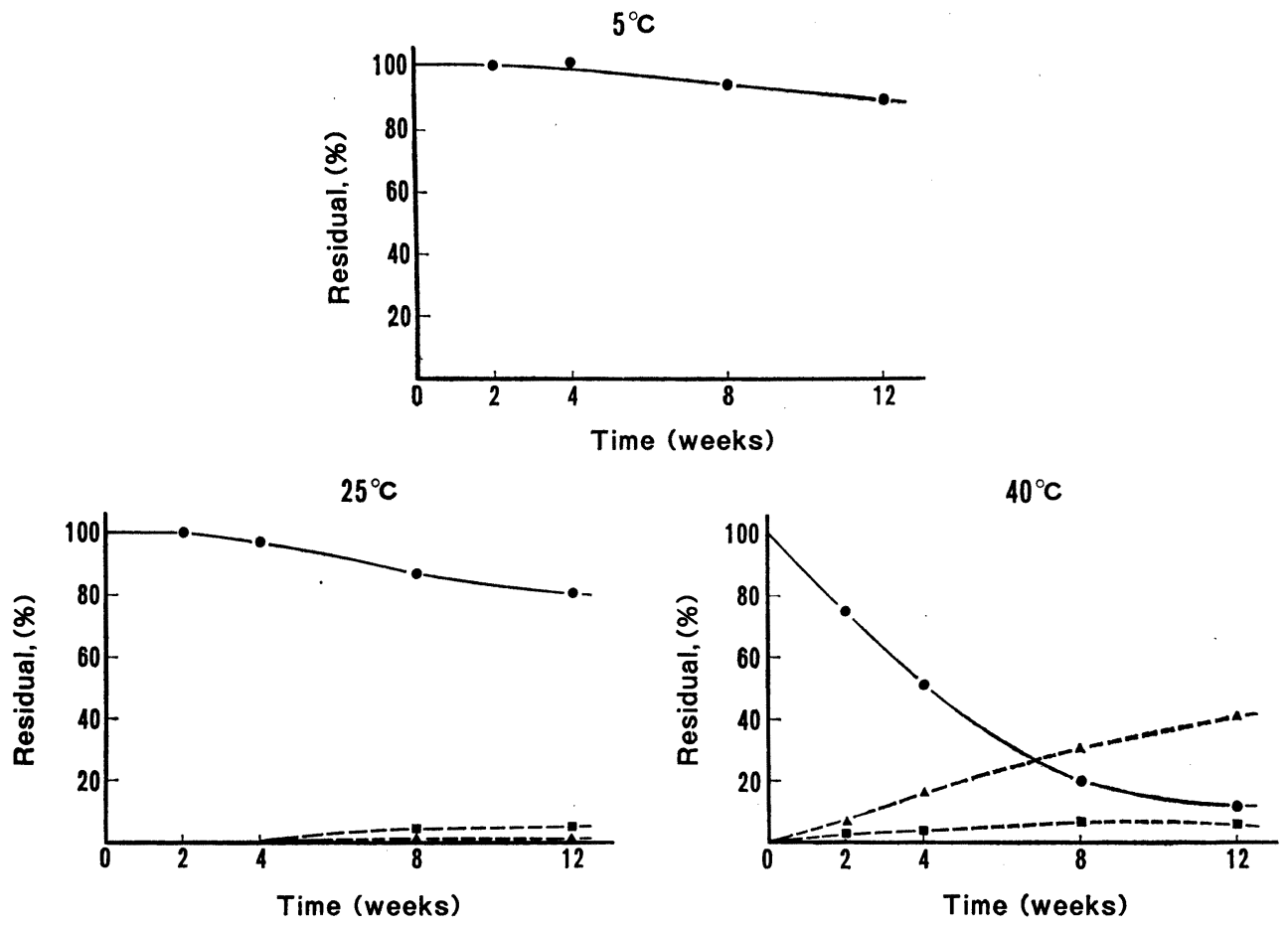

Fig. 4. Stability of $\mathrm{HC}-17-\mathrm{B}$ in Locoid Ointment Admixed with $\mathrm{ZO}$ , $\mathrm{HC}-17-\mathrm{B} ; \Delta, \mathrm{HC}-21-\mathrm{B} ; \mathbf{\square}, \mathrm{HC}$ 

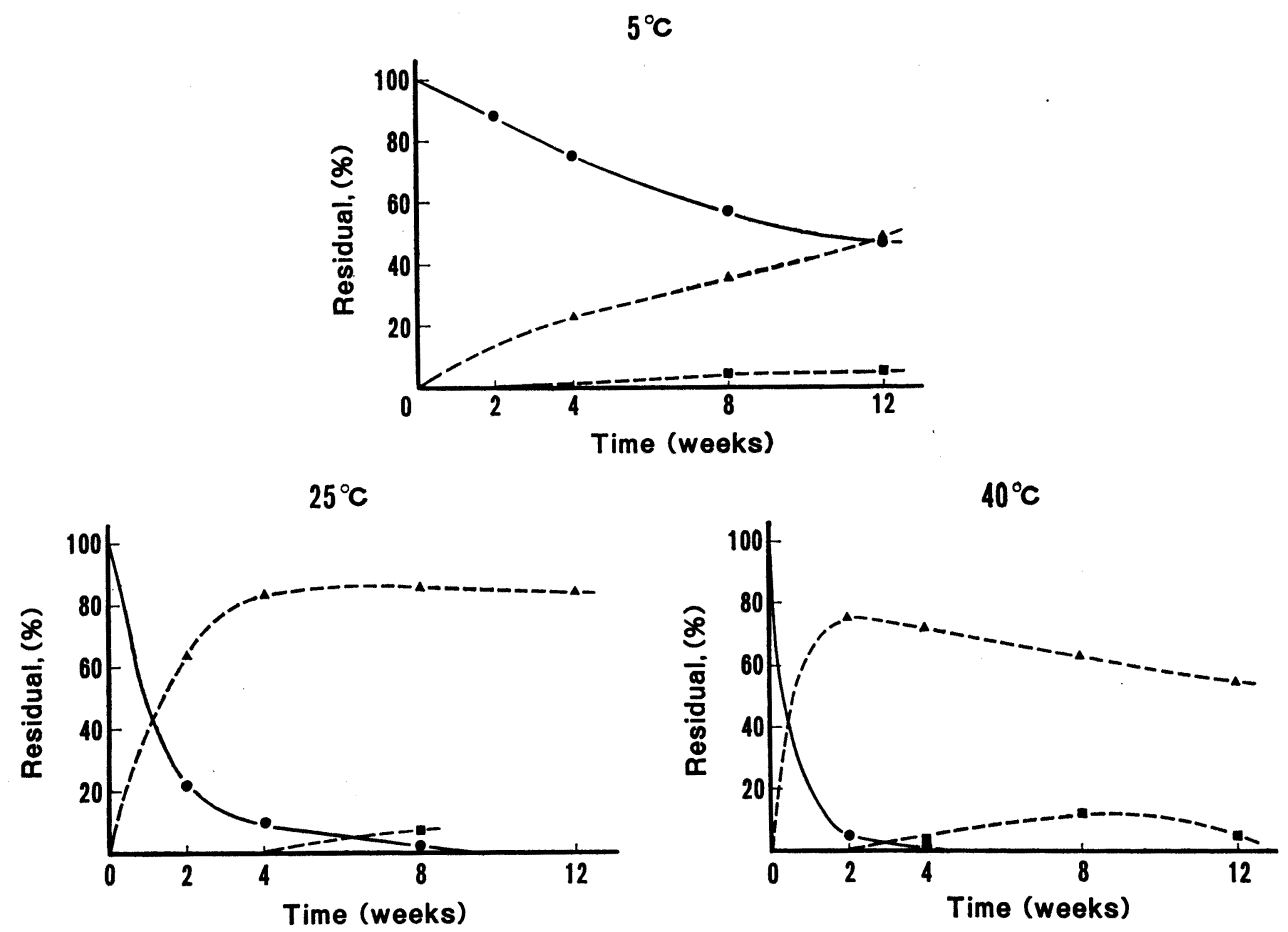

Fig. 5. Stability of $\mathrm{HC}-17-\mathrm{B}$ in Locoid ${ }^{\otimes}$ Ointment Admixed with Juvela Ointment , $\mathrm{HC}-17-\mathrm{B} ; \boldsymbol{\Delta}, \mathrm{HC}-21-\mathrm{B} ; \boldsymbol{\square}, \mathrm{HC}$.

謝辞 本論文作成にあたり，で指導いただいた本院薬 剂部町島 㤵部長に深く感謝します。

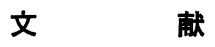

1）渡辺 靖, 永島敬士: 西日本皮㼪, 35, 649
(1973).

2) 竹田勇士, 久保田淳: 西日本皮底，36, 24 (1974).

3）久保田㴡, 山田和宏: 西日本皮席, 36, 31 (1974).

4) 川野泰明,有賀晶子, 柴 元靖: 薬剤学, 41(2), 71 (1981). 